\title{
CTS nos anos iniciais do ensino fundamental: abordagens para a temática água
}

Raimunda Leila José da Silva raimundaleila@gmail.com

http://orcid.org/0000-0002-2634-2290 Universidade de Brasília (UnB), Brasília Distrito Federal, Brasil

Roseline Beatriz Strieder roseline@unb.br

http://orcid.org/0000-0001-8965-8906 Universidade de Brasília (UnB), Brasília Distrito Federal, Brasil

\section{RESUMO}

Diante da defesa pela formação de cidadãos capazes de fazer uma leitura crítica da realidade, na perspectiva de Paulo Freire, e de que essa deve ser iniciada nos primeiros anos de escolarização, neste trabalho é discutida uma proposta de intervenção curricular, para os anos iniciais do ensino fundamental, balizada pelos pressupostos da Educação em Ciência-Tecnologia-Sociedade (CTS) e centrada na questão da água. A pesquisa que delineou o estudo foi a de abordagem qualitativa por entender que esta apresenta um desenho flexível, aberto e mantém o rigor investigativo em seu desenvolvimento. Além de uma análise de como essa temática é apresentada em documentos oficiais brasileiros direcionados ao ensino de Ciências nos anos inicias do ensino fundamental, são apresentadas abordagens possíveis de serem realizadas nesse contexto. Espera-se, com isso, contribuir para o universo de investigações preocupadas em contemplar os pressupostos da educação CTS nos anos iniciais do ensino fundamental na perspectiva do desenvolvimento de compromissos sociais por parte dos estudantes.

PALAVRAS-CHAVE: Ensino de Ciências. Ensino fundamental. CTS. 


\section{INTRODUÇÃO}

A situação global, permeada por controversas e incertezas relacionadas à ciência e tecnologia, leva à necessidade de buscar desenvolver uma educação científica que contribua para a formação de cidadãos capazes de lidar com problemas controversos e de diferentes naturezas, com condições de fazer uma leitura crítica da realidade (FREIRE, 1987). Isso pode ser efetivado por meio de propostas curriculares fundamentadas pela perspectiva Ciência-TecnologiaSociedade (CTS) (AULER, 2002; STRIEDER, 2012).

As questões relacionadas à CTS são de natureza complexa e controvertida e exigem uma discussão constante, com aprofundamentos gradativos. Sendo assim, defende-se que uma formação nesse sentido envolva recursividades. Nessa linha, inserções pontuais, nos anos finais do processo de escolarização básica, não são suficientes para se alcançar os propósitos almejados. Isso nos leva a sugerir o desenvolvimento de propostas curriculares CTS nos anos iniciais do ensino fundamental, algo pouco explorado nas pesquisas da área de Ensino até há pouco tempo (FAGUNDES et al., 2009; FERNANDES; MEGID NETO, 2012; OLIVEIRA; FREITAS, 2015).

Ressaltamos que essas ideias são defendidas por pesquisadores há algum tempo, mas somente recentemente têm ganhado notoriedade no campo da educação científica (GARVÃO; SLONGO, 2019). Essa notoriedade pode ser percebida, por exemplo, na edição especial desta revista (n.3 de 2019), que versa sobre o ensino de Ciências e Matemática nos anos iniciais e que possui 31 artigos publicados, dos quais 12 citam ou fundamentam-se na perspectiva CTS. Dentre os desafios da implementação da Educação CTS nos anos iniciais, esses trabalhos destacam, principalmente, questões associadas ao reconhecimento da importância e da viabilidade do ensino de ciências nessa faixa etária, e à formação dos professores polivalentes.

A nosso ver, a superação desses desafios perpassa pela análise de alguns fatores do contexto escolar. Ou seja, precisamos de parâmetros para o entendimento da realidade escolar, para, desta forma, propiciar subsídios aos professores, para que estes possam desenvolver propostas fundamentadas pela Educação CTS. Diante disso, cabe investigar, num primeiro momento, espaços curriculares, dinâmicas e estratégias para a inserção dessa perspectiva educacional nos anos iniciais do ensino fundamental. Com a intenção de aproximar essa investigação às práticas de sala de aula, por meio de reflexões em torno de uma proposta concreta, optamos por realizá-la a partir de uma questão socioambiental, a água.

Sendo assim, este trabalho tem por objetivo apresentar: (i) uma análise de documentos oficiais brasileiros direcionados ao ensino de ciências e aos anos iniciais do Ensino Fundamental, no que se refere à educação CTS e à temática água; e (ii) propostas de abordagens CTS, centradas no tema água, possíveis de serem realizadas nos anos iniciais do Ensino Fundamental. 


\section{PRESSUPOSTOS DA EDUCAÇÃO CTS}

Entendemos que a educação CTS abarca a efetiva articulação entre os três elementos da tríade, o que se dá a partir de três parâmetros: Racionalidade científica, Desenvolvimento tecnológico e Participação social, na perspectiva do desenvolvimento de Percepções, Questionamentos e/ou Compromissos sociais, que se configuram como propósitos educacionais dessa perspectiva (STRIEDER; KAWAMURA, 2017). A cada parâmetro vinculam-se distintas abordagens, que apresentam níveis de criticidade diferentes e, por meio delas, é possível estabelecer relações entre os parâmetros e propósitos educacionais. O quadro a seguir apresenta uma articulação entre esses parâmetros e propósitos da educação CTS, conforme demonstrado na figura 1 a seguir.

Figura 1 - Relação entre parâmetros e propósitos da educação CTS

\begin{tabular}{|c|c|c|c|}
\hline Propósitos & \multicolumn{3}{|c|}{ PARÂMETROS CTS } \\
\hline$\sqrt{b}$ & $\begin{array}{l}\text { Racionalidade } \\
\text { Científica }\end{array}$ & $\begin{array}{l}\text { Desenvolvimento } \\
\text { Tecnológico }\end{array}$ & Participação Social \\
\hline $\begin{array}{l}\text { Desenvolvimento de } \\
\text { Percepções }\end{array}$ & $\begin{array}{l}\text { (1R) Presença na } \\
\text { Sociedade }\end{array}$ & (1D) Questões Técnicas & (1P) Informações \\
\hline & $\begin{array}{l}(2 \mathrm{R}) \text { Beneficios e } \\
\text { Maleficios }\end{array}$ & $\begin{array}{l}\text { (2D) Organização e } \\
\text { Relações }\end{array}$ & $\begin{array}{l}(2 \mathrm{P}) \\
\text { Individuais }\end{array}$ \\
\hline $\begin{array}{l}\text { Desenvolvimento de } \\
\text { Questionamentos }\end{array}$ & $\begin{array}{l}\text { (3R) Condução das } \\
\text { Investigações }\end{array}$ & $\begin{array}{l}\text { (3D) Especificidades e } \\
\text { Transformações }\end{array}$ & $\begin{array}{l}\text { (3P) } \\
\text { Coletivas }\end{array}$ \\
\hline & $\begin{array}{l}\text { (4R) Investigações e } \\
\text { seus Produtos }\end{array}$ & $\begin{array}{l}\text { (4D) Propósitos das } \\
\text { produçōes }\end{array}$ & $\begin{array}{l}\text { (4P) Mecanismos de } \\
\text { Pressāo }\end{array}$ \\
\hline $\begin{array}{l}\text { Desenvolvimento de } \\
\text { Compromissos Sociais }\end{array}$ & (5R) Insuficiências & $\begin{array}{l}\text { (5D) Adequações } \\
\text { Sociais }\end{array}$ & (5P) Esferas Políticas \\
\hline
\end{tabular}

Fonte: Strieder e Kawamura (2017).

O desenvolvimento de percepções está associado ao estabelecimento de relações entre o conhecimento científico escolar e o contexto do aluno, com vistas a facilitar a compreensão e construção de conceitos por parte dos alunos ou contribuir para que eles passem a dar significado a esse conhecimento. No que se refere à Racionalidade, Desenvolvimento e Participação, envolve, respectivamente: reconhecer a presença da ciência e/ou da tecnologia no mundo (1R); compreender questões técnicas, como o funcionamento de aparatos tecnológicos (1D); e/ou, adquirir informações sobre questões/temas de relevância social (1P).

No desenvolvimento de questionamentos é almejada uma compreensão sobre a utilização responsável dos recursos naturais e aparatos tecnológicos e, no que se refere à Racionalidade, Desenvolvimento e Participação, está associado à: discussão de benefícios e malefícios dos produtos da ciência (2R); análise da condução das investigações científicas (3R) e das relações entre essas e seus produtos (4R); discussões sobre os contextos de produção, funcionamento e/ou uso de aparatos tecnológicos (2D) e sobre as especificidades e transformações acarretadas pelo desenvolvimento científico-tecnológico (3D); questionamentos sobre os propósitos que tem guiado a produção de novas tecnologias, com destaque para a não neutralidade da produção científico-tecnológica (4D); discussão sobre as possibilidades de participação social via decisões individuais $(2 \mathrm{P})$, coletivas (3P), mecanismos de pressão (4P). 
A perspectiva dos compromissos sociais envolve o desenvolvimento de competências para que a sociedade possa lidar com problemas de diferentes naturezas, tendo condições de fazer uma leitura crítica da realidade. Implica, por exemplo, discutir limitações do conhecimento científico para compreender e resolver problemas sociais (5R); enfatizar a importância de a sociedade almejar outro modelo de desenvolvimento, que busque satisfazer as necessidades básicas de uma determinada população e não somente gerar lucro econômico (5D); e, buscar uma cultura de participação no âmbito das políticas públicas, na definição de objetivos, meios para alcançá-los e maneiras de controlar sua implementação (5P). Essa perspectiva apresenta elementos comuns aos pressupostos freireanos de educação (FREIRE, 1987) já que objetiva problematizar contradições presentes na realidade com a intenção de identificar caminhos para sua superação/transformação.

Por fim, cabe destacar que essa matriz não deve ser entendida como "um instrumento para encaminhar as melhores práticas ou os melhores materiais CTS" (STRIEDER, 2012, p. 269). Nesse sentido, a utilizamos neste trabalho para refletir sobre os espaços curriculares e perspectivas de inserção da educação CTS nos anos iniciais, em especial, no que diz respeito às ênfases e conhecimentos a serem abordados. Porém, assim como coloca Strieder (2012), entendemos que as melhores práticas CTS não são as que contemplam todas essas abordagens visto que isso está associado aos contextos e espaços de atuação, como também ressaltam outros estudos que fazem uso desse instrumento para refletir sobre compreensões e práticas CTS (por exemplo: CARDOSO; ABREU; STRIEDER; SANTOS, 2015; LACERDA; LOPES; QUEIROZ, 2016; DECANTO; CAVALCANTI; ORTERMANN, 2016; SILVA; STRIEDER, 2017).

\section{CIÊNCIAS DA NATUREZA NUMA PERSPECTIVA CTS NOS ANOS INICIAIS}

Os anos iniciais do Ensino Fundamental possuem algumas peculiaridades com relação aos demais níveis de ensino básico. Dentre essas, destaca-se o fato de ser abordado por um professor polivalente, responsável por todas as áreas do conhecimento. Também, a faixa etária dos alunos tem sido apontada como algo importante a considerar, principalmente, devido à capacidade de abstração das crianças de 6 a 10 anos.

Quanto ao professor polivalente, há longa data, várias pesquisas (a exemplo de FUMAGALLI, 1998) têm apontado que esse, muitas vezes, foca seu trabalho no ensino da leitura, da escrita e das quatro operações básicas, deixando as ciências da natureza (assim como as humanas) para um segundo plano. Essa postura pode ser considerada um reflexo da formação desses professores, que também não tem enfatizado conteúdos de ciências da natureza (PIMENTA, 2014).

Por outro lado, entende-se que nesse nível de ensino o currículo não pode ser fragmentado e uma formação integral do sujeito é imprescindível; em função disso, um professor polivalente, com formação interdisciplinar, é essencial. Sendo assim, cabe investirmos em políticas públicas e ações voltadas à formação desse professor, contribuindo para que ele perceba a importância do ensino de ciências nesse nível de escolaridade e, além disso, tenha condições de abordá-lo de forma integrada aos demais conhecimentos. A nosso ver, como também defendido em outros trabalhos (a exemplo de MARQUES; MUENCHEN, 2019), o 
desenvolvimento de ações didáticas fundamentadas na educação CTS pode contribuir nesse sentido, visto que se trata de uma perspectiva interdisciplinar na qual os conhecimentos escolares são entendidos como meios para a compreensão e ação em torno de temáticas contemporâneas, marcadas por ciência e tecnologia (AULER, 2007).

Já no que se refere ao nível de abstração, vale ressaltar que as crianças não podem ser consideradas adultos em miniatura. Os vários estudos da psicologia cognitiva, em especial os realizados no âmbito da psicologia genética, nos auxiliam a compreender como as crianças constroem e compreendem o mundo (CARVALHO, 1997) e, articulado a isso, entende-se que elas possuem uma maneira particular de significar o mundo que as cerca e, enquanto integrantes da sociedade atual, devem ser responsáveis por este mundo desde tenra idade (FUMAGALLI, 1998). Como consta nos Parâmetros Curriculares Nacionais, as crianças nessa faixa etária "Podem aprender procedimentos simples de observação, comparação, busca e registro de informações, e também desenvolver atitudes de responsabilidade para consigo, com o outro e com o ambiente" (BRASIL, 1997, p.47).

Lorenzetti e Delizoicov (2001) também destacam a importância da alfabetização científica (AC) para a constituição da cidadania e resgatam uma série de trabalhos que refletem sobre essa questão, tanto do ponto de vista teórico quanto das práticas de sala de aula. Para esses autores, "a alfabetização científica pode e deve ser desenvolvida desde o início do processo de escolarização, mesmo antes que a criança saiba ler e escrever" (LORENZETTI; DELIZOICOV, 2001, p. 57). Também segundo esses autores, a AC é essencial para que o aluno possa ler, compreender e transformar a realidade que o cerca.

Além disso, as pesquisas que vêm sendo realizadas no campo da argumentação (a exemplo de LÓPEZ-RODRÍGUEZ; JIMÉNEZ-ALEIXANDRE, 2007) apontam que as crianças de 9 e 10 anos sustentam seus argumentos em conhecimentos científicos relevantes. Na mesma linha, Capecchi e Carvalho (2002) ao analisarem a realização de uma atividade de conhecimento físico com alunos de 8 a 10 anos, destacam que os alunos se esforçaram em buscar explicações para os fenômenos estudados e fazem uso de linguagem próxima a da ciência para isso.

Outro trabalho, que analisa a capacidade que os alunos possuem de rever posicionamentos e atitudes relacionadas a temáticas que os tocam, na perspectiva do desenvolvimento de ações sociais responsáveis é o de Mesquita (2019). Nesse trabalho, o autor analisa uma prática educativa que ocorreu em uma escola localizada em Belém/PA, com alunos do 5o ano e esteve centrada em discussões sobre a merenda escolar. Para Mesquita, a intervenção contribuiu para que os alunos desenvolvessem atitudes questionadoras em relação à merenda escolar o que, por sua vez, permitiu a realização de ações sociais transformadoras, a exemplo da escrita de uma carta endereçada à secretaria de educação, na qual os alunos relatam suas preferências e críticas com relação à qualidade da merenda.

Com a intenção de contribuir com essas discussões, preocupadas com a formação de alunos capazes de ler, compreender e transformar a realidade que os cerca, investigamos espaços curriculares e estratégias para a inserção da Educação CTS nos anos iniciais do Ensino Fundamental, considerando a questão 
das águas. Assim, com este trabalho, esperamos propiciar subsídios aos professores, para que estes possam desenvolver propostas fundamentadas pela Educação CTS nos anos iniciais.

\section{METODOLOGIA}

A pesquisa que delineou o estudo foi a de abordagem qualitativa por entender que esta apresenta um desenho flexível, aberto e mantém o rigor investigativo em seu desenvolvimento. Além disso, ela permite adaptações em circunstâncias do objeto de estudo, com foco central na compreensão dos fenômenos e na atribuição de seus significados (SAMPIERI; COLLADO; LUCIO, 2013).

Em primeiro momento, buscamos investigar espaços curriculares em Ciências da Natureza para a inserção da educação CTS e da temática água nos anos iniciais do Ensino Fundamental. Para tanto, realizamos uma leitura e análise dos seguintes documentos oficiais brasileiros relacionados a esse contexto: Parâmetros Curriculares Nacionais - PCN ${ }^{1}$ (BRASIL, 1997); Diretrizes Curriculares Nacionais - DCN (BRASIL, 2013); Guia de livros didáticos - PNLD, 2016 (BRASIL, 2015); e a Base Nacional Comum Curricular - BNCC (BRASIL, 2017). Essas leituras e análises foram realizadas nos moldes da Análise Textual Discursiva (MORAES; GALIAZZI, 2007) e a seguir é apresentado um resumo do metatexto elaborado.

Em um segundo momento, fundamentados pelos pressupostos teóricos apresentados e pelas discussões presentes nos documentos oficiais analisados, elaboramos uma proposta com possíveis abordagens para a temática água nos anos iniciais.

\section{RESULTADOS E DISCUSSÃO}

Quanto aos PCN, há discussões que sinalizam a perspectiva CTS, como pode ser percebido no excerto a seguir, que explicita as contribuições do ensino de ciências:

[...] para o questionamento do que se vê e ouve, para a ampliação das explicações acerca dos fenômenos da natureza, para a compreensão e valorização dos modos de intervir na natureza e de utilizar seus recursos, para a compreensão dos recursos tecnológicos que realizam essas mediações, para a reflexão sobre questões éticas implícitas nas relações entre Ciência, Sociedade e Tecnologia (BRASIL, 1997, p.22, grifo nosso).

Nas DCN (BRASIL, 2013) há uma preocupação explícita com a articulação entre os conhecimentos específicos de cada componente curricular e "temas abrangentes e contemporâneos, que afetam a vida humana em escala global, regional e local, bem como na esfera individual" (BRASIL, 2013, p. 115). Dentre esses temas, encontram-se: saúde, sexualidade e gênero, vida familiar e social, direitos das crianças e adolescentes, preservação do meio ambiente, consumo, educação fiscal, trabalho, ciência e tecnologia e diversidade cultural. Entende-se que a discussão desses temas pode ser realizada com base nos propósitos da educação CTS, contribuindo para a formação cidadã. 
No guia do PNLD 2016 (BRASIL, 2015) são enfatizadas as contribuições do ensino de ciências nesse nível de escolaridade; como consta no documento:

Espera-se que, ao final dos anos iniciais, os estudantes tenham adquirido elementos básicos que possibilitem, ainda que em nível introdutório, utilizar a aprendizagem de Ciências para informar, explicar, argumentar e se posicionar no dia a dia (BRASIL, 2015, p.14).

Essa unidade de significado exemplifica que nesse documento também há sinalizações para uma educação CTS, no sentido em que a aprendizagem em ciências é vista como um meio para o desenvolvimento de competências associadas à formação cidadã. Além disso, o documento aponta que algumas das coleções analisadas contemplam abordagens CTS (embora, nem sempre, façam referência explícita à CTS). Os excertos a seguir exemplificam essas sinalizações:

\footnotetext{
Chamando para o debate - problema levantado para discutir questões envolvendo ética, saúde e cidadania e trabalhar tópicos de Ciência, Tecnologia e Sociedade (CTS); (BRASIL, 2015; p.50, grifo nosso).
}

Articulações de conteúdos a partir de temas abrangentes, que afetam a vida humana de forma global, local e individual, estão presentes, por exemplo, quando se discute a tecnologia e a eletricidade de forma articulada ao seu desenvolvimento histórico e às reflexões sobre os seus usos na sociedade (BRASIL, 2015; p.28).

No primeiro excerto há menção explícita à CTS; o segundo evidencia interrelações CTS ao mencionar a tecnologia e os usos sociais vinculados a determinado conhecimento científico.

Na BNCC (BRASIL, 2017), também foram encontradas unidades de significado que apontam para uma educação CTS. Por exemplo, dentre as competências específicas de Ciências da Natureza para o EF estão: "Dominar processos, práticas e procedimentos da investigação científica, de modo a sentir segurança no debate de questões científicas, tecnológicas, socioambientais" (BRASIL, 2017, p. 323) e "Avaliar aplicações e implicações políticas, socioambientais e culturais da ciência e de suas tecnologias para propor alternativas aos desafios do mundo contemporâneo" (BRASIL, 2017, p. 323).

Além disso, os objetos de conhecimento propostos (Consumo consciente; Reciclagem; Seres vivos no ambiente; Ciclo hidrológico) sinalizam para abordagens CTS, no sentido em que contemplam preocupações em torno das implicações do uso de recursos naturais e aparatos tecnológicos, buscando conscientizar a todos sobre o uso responsável dos mesmos. A seguir, apresentamos um trecho mencionado no documento, e que exemplificam essa sinalização: instrumentos óticos na saúde e na observação do céu, a produção de material sintético e seus usos, as aplicações das fontes de energia e suas aplicações e, até mesmo, o uso da radiação eletromagnética para diagnóstico e tratamento médico, entre outras situações, são exemplos de como ciência e tecnologia, por um lado, viabilizam a melhoria da qualidade de vida humana, mas, por outro, ampliam as desigualdades sociais e a degradação do ambiente (BRASIL, 2017, p. 327). 
Particularmente no que diz respeito ao tema água, nos PCN está explicito que se trata, juntamente com poluição, energia, máquinas e culinária, de um tema "já consagrado" para esse nível de ensino. Dentre as discussões a serem realizadas, encontram-se: as relações entre água e seres vivos e entre água, lixo, solo e saneamento básico; captação, distribuição e armazenamento da água; os modos domésticos de tratamento da água; o destino das águas servidas; a presença da água no planeta e suas transformações; características/propriedades da água; etc. Também, vale destacar alguns excertos que apresentam críticas às abordagens ingênuas em torno dessa temática:

Os fundamentos científicos devem subsidiar a formação de atitudes dos alunos. Não basta ensinar, por exemplo, que não se deve jogar lixo nas ruas ou que é necessário não desperdiçar materiais, como água, papel ou plástico. Para que essas atitudes e valores se justifiquem, para não serem dogmas vazios de significados, é necessário informar sobre as implicações ambientais dessas ações. Nas cidades, lixo nas ruas pode significar bueiros entupidos e água de chuva sem escoamento, favorecendo as enchentes e a propagação de moscas, ratos ou outros veículos de doenças. (BRASIL, 1997, p. 37)

É comum, por exemplo, discutir-se a preservação de energia e de água potável ou o risco da automedicação a partir de uma perspectiva simplesmente individual, restringindo-se a recomendações do tipo "apague a luz do corredor" e "não deixe a torneira pingando", ou "evite a automedicação", deixando-se de lado variáveis gravemente mais relevantes como a política econômica de produção de equipamentos energeticamente perdulários, como automóveis de alta potência e geladeiras mal isoladas ou a propaganda de medicamentos e sua venda indiscriminada. O alcance político de tais questões éticas poderia reverter em imediato benefício para a população, pois uma efetiva proibição da venda de medicamentos sem receita colocaria a poderosa indústria farmacêutica mobilizada a favor da ampliação do atendimento médico (BRASIL, 1997, p. 42).

Nas DCN, na parte referente ao ensino de ciências nos anos iniciais, não há discussões sobre os conteúdos a serem abordados e, portanto, não há menções à temática água. Por outro lado, na versão preliminar da BNCC, essa temática está presente em vários momentos, principalmente, nos quadros que detalham articulações entre as unidades temáticas, objetos de conhecimento e habilidades para cada ano do Ensino Fundamental (p.333-339). Essa presença, em várias unidades temáticas e anos, nos leva a compreender que a questão da água é uma temática transversal aos anos iniciais. Inclusive, na explicação dos objetivos relacionados à unidade temática "Matéria e Energia", essa problemática recebe destaque, junto com o hábito e uso sustentável de recursos naturais e energéticos, como mostra o excerto a seguir:

Espera-se também que os alunos possam reconhecer a importância, por exemplo, da água, em seus diferentes estados, para a agricultura, o clima, a conservação do solo, a geração de energia elétrica, a qualidade do ar atmosférico e o equilíbrio dos ecossistemas (BRASIL, 2017, p.323).

Apesar dessa preocupação, as habilidades desenvolvidas a partir de discussões que envolvem a água, na maioria das vezes, não estão associadas à problemática das águas propriamente dita. Como mostram os excertos a seguir, extraídos da BNCC, a água é apenas cenário para a abordagem de conceitos e/ou compreensão de determinados fenômenos: 
(EF02Cl08) Comparar o efeito da radiação solar (aquecimento e reflexão) em diferentes tipos de superfície (água, areia, solo, superfícies escura, clara e metálica etc.).

(EF03CI02) Experimentar e relatar o que ocorre com a passagem da luz através de objetos transparentes (copos, janelas de vidro, lentes, prismas, água etc.), no contato com superfícies polidas (espelhos) e na intersecção com objetos opacos (paredes, pratos, pessoas e outros objetos de uso cotidiano).

(EF03Cl07) Identificar características da Terra (como seu formato esférico, a presença de água, solo etc.), com base na observação, manipulação e comparação de diferentes formas de representação do planeta (mapas, globos, fotografias etc.).

(EFO4CI03) Concluir que algumas mudanças causadas por aquecimento ou resfriamento são reversíveis (como as mudanças de estado físico da água) e outras não (como o cozimento do ovo, a queima do papel etc.).

Em três habilidades há indícios de preocupação com a temática das águas na medida em que comparecem discussões sobre a importância da água para a vida e sobre o ciclo da água:

(EF02Cl05) Investigar a importância da água e da luz para a manutenção da vida de plantas em geral.

(EF05CI02) Aplicar os conhecimentos sobre as mudanças de estado físico da água para explicar o ciclo hidrológico e analisar suas implicações na agricultura, no clima, na geração de energia elétrica, no provimento de água potável e no equilíbrio dos ecossistemas regionais (ou locais).

(EF05Cl03) Selecionar argumentos que justifiquem a importância da cobertura vegetal para a manutenção do ciclo da água, a conservação dos solos, dos cursos de água e da qualidade do ar atmosférico.

Apenas em duas habilidades há uma preocupação explícita com atitudes de preservação do meio ambiente e estas estão associadas a ações individuais de diminuição de consumo cotidiano:

(EF05CI04) Identificar os principais usos da água e de outros materiais nas atividades cotidianas para discutir e propor formas sustentáveis de utilização desses recursos.

(EF05CI05) Construir propostas coletivas para um consumo mais consciente e criar soluções tecnológicas para o descarte adequado e a reutilização ou reciclagem de materiais consumidos na escola e/ou na vida cotidiana.

Outro aspecto que chama atenção é pouca ênfase em discussões sobre saneamento, que é mencionado apenas em habilidades do 7ํano, apesar de receber destaque nas justificativas para o Ensino de Ciências:

Para debater e tomar posição sobre alimentos, medicamentos, combustíveis, transportes, comunicações, contracepção, saneamento e manutenção da vida na Terra, entre muitos outros temas, são imprescindíveis tanto conhecimentos éticos, políticos e culturais quanto científicos. Isso por si só já justifica, na educação formal, a presença da área de Ciências da Natureza, e de seu compromisso com a formação integral dos alunos (BRASIL, 2017, p. 319). 
Por meio da análise do PNLD, constatamos que o tema água está explícito no sumário da maioria das coleções (em 12 das 15 coleções destinadas ao 2 ㅇ e 3으 anos e em 10 das 13 coleções destinadas ao 4 ㅇ e 5 o anos) e encontra-se associado a diferentes conteúdos, como apresentam as tabelas 1 e 2 , organizadas por ciclo (Quadro 1: coleções do primeiro ciclo, ou seja, 2ㅇ e 3ㅇ anos; quadro 2: coleções do segundo ciclo, ou seja, 4ํ e 5으 ano).

Quadro 1 - Relação de conteúdos presentes nas obras de 2ํe 3ํano, organizadas por coleção

\begin{tabular}{|c|c|c|c|c|c|c|c|c|c|c|c|c|c|c|c|}
\hline \multirow{2}{*}{ Categoria } & \multicolumn{15}{|c|}{ Coleções de $2^{\circ}$ e $3 \circ$ anos } \\
\hline & 1 & 2 & 3 & 4 & 5 & 6 & 7 & 8 & 9 & 10 & 11 & 12 & 13 & 14 & 15 \\
\hline \multicolumn{16}{|l|}{ Conhecendo o Planeta } \\
\hline $\begin{array}{lr}\text { Usos } & \text { e } \\
\text { transformações } & \text { de } \\
\text { recursos naturais } & \end{array}$ & & & & & & & & & & & & & & & \\
\hline $\begin{array}{l}\text { Propriedades e/ou } \\
\text { Fenômenos físicos e } \\
\text { químicos }\end{array}$ & & & & & & & & & & & & & & & \\
\hline $\begin{array}{ll}\text { Saneamento } & \text { e/ou } \\
\text { tratamento } & \end{array}$ & & & & & & & & & & & & & & & \\
\hline Problemas ambientais & & & & & & & & & & & & & & & \\
\hline $\begin{array}{l}\text { Ações } \\
\text { responsáveis/cuidados } \\
\text { com o ambiente }\end{array}$ & & & & & & & & & & & & & & & \\
\hline
\end{tabular}

Fonte: Autoria própria (2017).

A partir desse quadro, percebe-se que as discussões sobre água, presentes no 10 ciclo, estão associadas aos seguintes conteúdos: conhecendo o planeta; usos e transformações de recursos naturais; propriedades e/ou fenômenos físicos e químicos associados à água; saneamento e/ou tratamento de água; problemas ambientais; ações responsáveis e/ou cuidados que devemos ter com o meio ambiente. Também, que predominam discussões relacionadas às características do planeta e aos problemas ambientais. Em segundo plano, nesse ciclo, são abordadas questões relacionadas a usos e transformações de recursos naturais e propriedades e/ou fenômenos físicos e químicos.

Os conteúdos abordados no 1ำ ciclo são retomados no 2 - ciclo, como indica o Quadro 2. Além deles, são discutidos direitos à água de qualidade e fontes de energia. Nessas coleções, são enfatizadas questões sobre saneamento e ações responsáveis/cuidados com o ambiente e a saúde. 
Quadro 2 - Relação de conteúdos presentes nas obras de 4ㅇe 5o ano, organizados por coleção

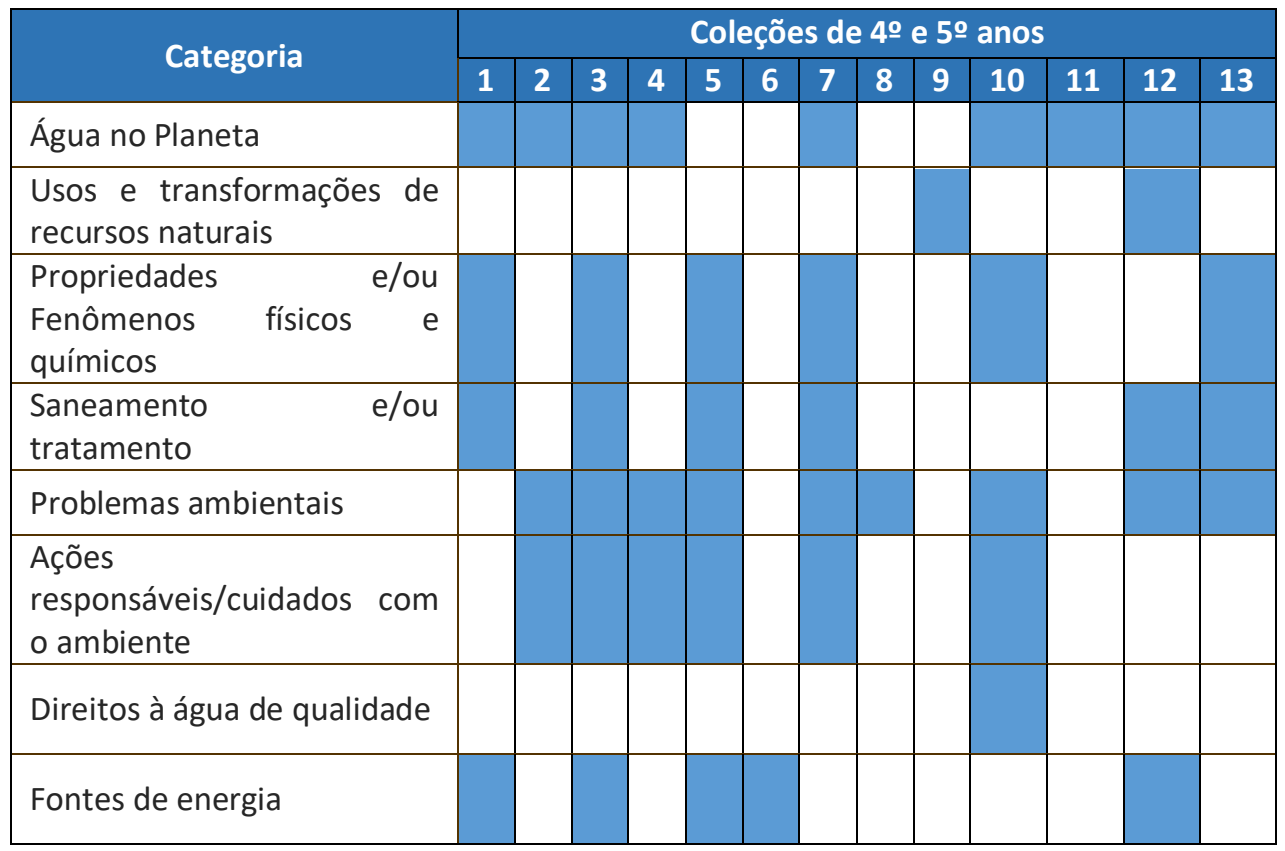

Fonte: Autoria própria (2017).

Além disso, e com relação às atividades propostas nas coleções destinadas aos 2 ㅇ e 3 ㅇ anos, merece destaque: a visita a estações de tratamento (C15) e a realização de um debate para decidir sobre a implantação de uma usina em uma cidade fictícia (C10). Nas coleções destinadas ao 4으 e 5으 ano, por sua vez, merece destaque a sugestão de abordagens interdisciplinares em C9, que, como destacado na Análise Crítica da obra, para iniciar a discussão dos estados físicos da água, é apresentada uma ilustração representando o Titanic e o bloco de gelo com o qual ele se chocou e, a partir dessa imagem, é sugerido ao professor complementar a abordagem, incorporando a análise de documentos históricos, como reportagens sobre a inauguração do "grandioso" navio e manchetes posteriores ao seu naufrágio. Também, nesse item encontra-se um infográfico de uma estação de tratamento de água (C9) e a análise e discussão de faturas de consumo de água, (C9 e C12).

Diante dessa análise, concluímos que há espaços curriculares nos anos inicias para abordagens CTS e sobre a temática das águas. Vale esclarecer que, embora haja discussões que se aproximam do defendido no âmbito da educação CTS, essas, em geral, estão associadas a perspectivas menos críticas de CTS. Ou seja, vinculam-se ao desenvolvimento de percepções (STRIEDER; KAWAMURA, 2017) e a discussões sobre os usos conscientes dos recursos naturais, o que pode ser associado aos níveis menos críticos do desenvolvimento de questionamentos (STRIEDER; KAWAMURA, 2017). Assim, entendemos ser relevante pensar em propostas de abordagens CTS para essa temática, em especial, no que se refere à discussão de elementos mais críticos. Essas propostas são apresentadas na sequência. 


\section{ABORDAGENS CTS PARA A TEMÁTICA ÁGUA NOS ANOS INICIAIS: UMA PROPOSTA}

Segue a apresentação dessa proposta organizada de acordo com os propósitos da educação CTS, associados ao desenvolvimento: de percepções, questionamentos e compromissos sociais.

\section{Desenvolvimento de percepções}

Com a intenção de contribuir para o desenvolvimento de percepções, uma discussão possível de ser realizada, e que está associada à presença da ciência na sociedade (R1), diz respeito aos conhecimentos científicos escolares relacionados ao tema água. Nesse caso, podem ser discutidas as características da água (cheiro, cor, sabor, forma), a importância da água para vida, estados físicos, usos da água, fontes e reservatórios, doenças veiculadas pela água e ciclo da água.

Quanto ao desenvolvimento tecnológico, poderiam ser abordadas questões técnicas, associadas, por exemplo, às estações de tratamento, ao percurso da água para chegar até nossas casas e para onde ela vai depois que a utilizamos (saneamento, rede de esgoto), as quais se enquadram no nível D1.

Também, é importante reconhecer que há problemas relacionados ao assunto, o que envolve entrar em contato com questões como a falta de água em casa, no bairro/cidade (quando houver), além da questão da escassez mundial.

Esses conhecimentos, em geral, estão presentes nos livros didáticos aprovados pelo PNLD, como indica a análise que realizamos do Guia dos Livros Didáticos.

\section{Desenvolvimento de questionamentos}

Em uma perspectiva mais crítica, podem ser realizadas discussões sobre os aspectos positivos e negativos desses conhecimentos/produtos da ciência e da tecnologia (R2). Por exemplo: saber propriedades e características da água permite que ampliemos o espectro de possibilidades quanto ao uso da água, mas, por outro lado, faz com que utilizamos mais e, também, que ocorra a contaminação da água (pelas indústrias, por exemplo); ou seja, trata-se de abordar que os produtos da ciência e tecnologia trazem tanto benefícios quanto malefícios à sociedade. Também, podem ser discutidos conteúdos relacionados à natureza da ciência (R3), por exemplo: os cientistas que contribuíram para a construção dos conhecimentos sobre a água e as ações que, em geral, foram desenvolvidas pelos cientistas nesse processo. Ainda sobre a natureza da ciência, mas associado ao reconhecimento de relações entre as investigações e seus produtos, podem ser apresentadas pesquisas atuais relacionadas a esse assunto (exemplo: filtros de água baseados em conhecimentos de nano); quem são, onde e como os cientistas trabalham; como conseguem seus recursos, se estão organizados em grupos ou comunidades, como é o seu dia a dia, etc.

Associado ao desenvolvimento tecnológico, podem ser discutidas as relações entre aparatos e a sociedade (D2): o que é preciso para a estação de captação ou 
tratamento funcionar (quem/quantas pessoas trabalham numa estação de tratamento ou estão envolvidas na distribuição)? Quais contribuições esse aparato traz para a sociedade (comunidade do entorno)? Há estações em nosso bairro/município/região? Conhecemos pessoas que trabalham nessas estações? Além disso, relacionado à abordagem D3, especificidades e transformações associadas a essa tecnologia, podem ser enfocadas: Quando não tinha estação de tratamento/distribuição como as pessoas faziam para ter água potável? Quais as transformações sociais acarretadas por essa tecnologia? Em que sentido/até que ponto isso facilitou a vida em sociedade? Afetou de forma negativa? Também, podem ser abordados propósitos associados a essa tecnologia, ou relações entre ela e modelos de desenvolvimento, o que está relacionado ao nível D4. Isso envolve, por exemplo, a discussão da seguinte questão: apesar de toda essa tecnologia/conhecimento, porque alguns bairros/comunidades/países têm problemas com a água? Ou seja, discutir sobre a questão da falta de acesso e as relações entre o progresso tecnológico e as necessidades básicas da população como um todo; tecnologia e desigualdade social.

Sobre a participação social, podem ser realizadas discussões sobre o consumo "individual" de água, com vistas à conscientização sobre a necessidade de diminuir o consumo de água em nossas residências, escolas, etc. Ou seja, não podemos desperdiçar e nem poluir. Mas, ao mesmo tempo, temos consciência sobre a necessidade de usar água. Ou seja, perpassa a discussão de aspectos positivos e negativos associados ao uso desse recurso natural com vistas a decisões individuais. Num nível mais crítico, estão as discussões sobre a disponibilidade de água (reservatório e ciclos) e os usos por diferentes setores (agricultura, indústria, residências, etc.); além das implicações de não se ter água potável disponível no planeta em quantidades suficientes. Ou seja, precisamos de ações mais amplas e coletivas, oriundas de decisões que envolvam a sociedade como um todo, pois a água é usada para muitas coisas e não só para nosso consumo doméstico. Assim, não basta economizar água em casa ou não poluir os rios; o consumo e desperdício de outros bens também trazem consequências com relação à água. Além disso, pode ser discutido como está a situação das águas (disponibilidades, tratamento, consumo) em nossa casa/bairro/município/país. Todos têm acesso à água potável e rede de esgoto? Quem não tem? O que caracteriza essas comunidades (seca/falta de chuva, pobreza, etc.). A intenção é indicar que há relações de poder envolvidas nessa questão e, a partir, disso, contribuir para o desenvolvimento de mecanismos de pressão.

\section{Desenvolvimento de compromissos sociais}

Por fim, na perspectiva dos compromissos sociais, no que se refere à racionalidade científica (R5), podem ser abordadas as insuficiências do conhecimento científico para resolver problemas da sociedade - no caso da escassez da água, por exemplo, o problema não diz respeito somente à ciência, trata-se de uma situação complexa, que envolve questões políticas, econômicas e sociais. Os conhecimentos da ciência nos ajudam a entender e resolver uma série de problemas, mas os contextos/situações/problemas são complexos e são necessários conhecimentos de diferentes áreas ou campos. 
Também, e relacionado ao desenvolvimento tecnológico, pode-se discutir a necessidade de adequações sociais (D5), ou seja, perspectivas de desenvolvimento tecnológico para resolver o problema da água e que não estejam voltadas ao lucro econômico, mas ao bem estar da população. Isso abarca a discussão de questões como: o que poderia ser feito para diminuir o problema da falta de água? Quais tecnologias deveríamos/poderíamos desenvolver? Também, poderiam ser estudados exemplos como o caso da construção de cisternas do nordeste do Brasil.

Quanto à participação social, podem ser discutidas políticas públicas locais/mundiais relacionadas ao assunto, atores que as propõem (e a necessidade de participação cidadã), como se dá o processo no âmbito do bairro, município, estado, país, organizações mundiais (protocolos assinados entre os países), etc.

\section{CONSIDERAÇÕES FINAIS}

Esta investigação parte de uma preocupação em inserir discussões sobre CTS nos anos iniciais do ensino fundamental, em especial, porque entendemos que se trata de uma questão complexa, que exige recursividades. Dessa forma, e como primeiro olhar para a questão, optamos por buscar espaços curriculares e elaborar uma proposta com possíveis abordagens CTS para a temática água.

A análise dos documentos oficiais indica que há espaços curriculares, nos anos iniciais, para a inserção de propostas fundamentadas pela educação CTS e que abordem a questão das águas. Porém, esses espaços estão associados a perspectivas menos críticas de CTS. Vinculam-se ao desenvolvimento de percepções entre o conhecimento científico escolar e a realidade dos alunos, e a discussões sobre os usos conscientes dos recursos naturais, o que pode ser associado aos níveis menos críticos do desenvolvimento de questionamentos.

Diante disso, propusemos uma série de abordagens possíveis para essa temática, em especial, no que se refere à discussão de elementos mais críticos. Essas abordagens fundamentaram-se na perspectiva CTS defendida neste trabalho e estão associadas à Racionalidade Científica, Desenvolvimento tecnológico e Participação Social com vistas ao desenvolvimento de Percepções, Questionamentos e Compromissos Sociais. Cabe esclarecer que esses Propósitos e Parâmetros devem ser entendidos como complementares em termos de formação científica, correspondendo a diferentes situações, contextos escolares e possibilidades de atuação, ou mesmo, a momentos sucessivos de apropriação de intenções. Assim, embora as abordagens estejam associadas a níveis de criticidade distintos, não representam uma progressão no sentido do que deve ser discutido no contexto educacional. Em função disso, entendemos que é preciso realizar o estudo da realidade com a qual os alunos se encontram para definir situações problemas e conteúdos a serem investigados com os alunos. Também, dentre as atividades a serem desenvolvidas, chamamos atenção para a socialização dos resultados já que essa ação pode contribuir para o desenvolvimento de compromissos sociais.

Como continuidade desta investigação pretende-se realizar as seguintes ações: análise dos livros didáticos de Ciências dos anos iniciais; análise de documentos oficiais e livros didáticos dos demais componentes curriculares dos anos inicias, com vistas à abordagem interdisciplinar do tema; discussão da 
proposta com professores dos anos iniciais; elaboração de uma sequência de aulas e sua implementação junto aos alunos e, a partir disso, reflexões em torno dos limites e potencialidades dessa implementação quanto aos propósitos da educação CTS. 


\title{
STS in the early years of elementary school: approaches to the water
}

\begin{abstract}
In view of the defense for the formation of citizens capable of making a critical reading of reality, in the perspective of Paulo Freire, and that this should be started in the first years of schooling, this work discusses a proposal for curricular intervention, for the initial years of elementary education, guided by the assumptions of Education in Science-TechnologySociety (STS) and focused on the issue of water. The research that outlined the study was that of a qualitative approach because it understands that it has a flexible, open design and maintains investigative rigor in its development. In addition to an analysis of how this theme is presented in official Brazilian documents aimed at science teaching in the early years of elementary school, possible approaches to be carried out in this context are presented. With this, it is expected to contribute to the universe of investigations concerned with contemplating the assumptions of STS education in the early years of elementary school in the perspective of the development of social commitments by students.
\end{abstract}

KEYWORDS: Science teaching. Elementary School. STS. 


\section{NOTAS}

1 Embora o PCN tenha sido revogado pelas novas DCN e pela BNCC, entendemos que sua análise é importante, em especial, porque esses novos documentos (também analisados nesta investigação) ainda estão em processo de implantação.

\section{REFERÊNCIAS}

AULER, D. Enfoque Ciência-Tecnologia-Sociedade: pressupostos para o contexto brasileiro. Ciência \& Ensino. v. 1, n. especial, 2007.

AULER, D. Interações entre Ciência-Tecnologia-Sociedade no Contexto da Formação de Professores de Ciências. 2002. 248 f. Tese (Doutorado em Educação) - Universidade Federal de Santa Catarina, Florianópolis, 2002.

BRASIL. Ministério da Educação, Secretária de Educação Básica. Guia de livros didáticos: PNLD 2016: Ciências: ensino fundamental anos iniciais, 2015.

BRASIL. Ministério da Educação. Base Nacional Comum Curricular - Educação é a Base. Brasília, Distrito Federal, 2017.

BRASIL. Ministério da Educação. Diretrizes Curriculares Nacionais Gerais da Educação Básica. Brasília: MEC, SEB, DICEI, 2013.

BRASIL. Secretaria de Educação Fundamental. Parâmetros curriculares nacionais: ciências naturais. Brasília: MEC/SEF, 1997.

CAPECHI, M. C.; CARVALHO, A. M. de. Argumentação em aula de conhecimento físico com crianças na faixa de oito a dez anos. Investigações em Ensino de Ciências, v. 5, n. 3, 2002. p.171-189.

CARDOSO, Z.; ABREU, R.; STRIEDER, R.; SANTOS, W. Radioatividade e CTS: Resultados de uma implementação. In: ENCONTRO NACIONAL DE ENSINO DE PESQUISA EM EDUCAÇÃO EM CIÊNCIAS, 10, 2015, Águas de Lindóia-SP. Anais [...]. Águas de Lindóia-SP, 2015.

CARVALHO, A. M. Ciências no Ensino Fundamental. Cadernos de Pesquisa. n. 101, p. 152-168, 1997.

DECONTO, D.; CAVALCANTI, C. J.; OSTERMANN, Fernanda. Perspectiva Ciência, Tecnologia e Sociedade na Formação Inicial de Professores de Física: Estudando Concepções A Partir de uma Análise Bakhtiniana. Alexandria - Revista de Educação em Ciência e Tecnologia, v.9, n.2, p.87-119, novembro 2016.

FAGUNDES, S.; PICCINI, I.; LAMARQUE, T.; TERRAZZAN, E. Produções em educação em ciências sob a perspectiva CTS/CTSA. In: ENCONTRO NACIONAL DE ENSINO DE PESQUISA EM EDUCAÇÃO EM CIÊNCIAS, 7, 2009, Florianópolis-SC. Anais [...]. Florianópolis-SC, 2009. 
FERNANDES, R.; MEGID NETO, J. Modelos educacionais em 30 pesquisas sobre práticas pedagógicas no ensino de Ciências nos anos iniciais da escolarização. Investigações em Ensino de Ciências, v. 17, n. 3, pp. 641-662, 2012.

FREIRE, P. Pedagogia do Oprimido. 17ạ ed. Rio de Janeiro: Paz e Terra, 1987.

FUMAGALLI, L. O ensino de ciências naturais no nível fundamental de educação formal: argumentos a seu favor. In: WEISSMANN, Hilda (Org.). Didática das ciências naturais: contribuições e reflexões, Porto Alegre: ArtMed, 1998.

GARVÃO, M.; SLONGO, I. I. P. O ensino de ciências no currículo oficial dos anos iniciais: uma leitura da sua história. ACTIO, Curitiba, v. 4, n. 3, p. 675-700, set./dez. 2019.

LACERDA, N.; LOPES, E.; QUEIRÓS, W. Lixo eletrônico como tema CTS: estudo exploratório sobre compreensão dos estudantes. Indagatio Didactica, v. 8, n. 1, p. 1279-1295, julho 2016.

LÓPEZ-RODRÍGUES, R.; JIMÉNEZ-ALEIXANDRE, M. P. ¿Podemos cazar ranas? Calidad de los argumentos de alumnado de primaria y desempeño cognitivo en el estudio de una charca. Enseñanza de las ciencias: revista de investigación y experiencias didácticas [online], v. 25, n. 3, p. 309-324, 2007.

LORENZETTI, L.; DELIZOICOV, D. Alfabetização Científica no contexto das Séries Iniciais. Ensaio - Pesquisa em Educação em Ciências, Belo Horizonte, v.03, n.01, p.45-61, jan-jun, 2001.

MARQUES, S. G.; MUENCHEN, C. Possibilidades e desafios para a formação permanente de educadores dos anos iniciais: uma revisão de literatura. ACTIO, Curitiba, v. 4, n. 3, p. 411-429, set./dez. 2019.

MESQUITA, A. S. de Ação social responsável: práticas de letramento científico e matemático nos anos iniciais do ensino fundamental. ACTIO, Curitiba, v. 4, n. 3, p. 309-326, set./dez. 2019.

MORAES, R.; GALLIAZZI, M. do C. Análise Textual Discursiva. Ijuí: Unijuí, 2007.

OLIVEIRA, E.; FREITAS, D. de. A produção acadêmica acerca do ensino de Ciências nos anos iniciais nas revistas Ensaio e RBPEC: o lugar da perspectiva ciência, tecnologia e sociedade. In: ENCONTRO NACIONAL DE ENSINO DE PESQUISA EM EDUCAÇÃO EM CIÊNCIAS, 10, 2015, Águas de Lindóia-SP. Anais [...]. Águas de Lindóia-SP, 2015.

PIMENTA, S. G. A formação de professores para a Educação Infantil e para os anos iniciais do Ensino Fundamental: análise do currículo dos cursos de Pedagogia de instituições públicas e privadas do Estado de São Paulo. In: ENCONTRO NACIONAL DE DIDÁTICA E PRÁTICA DE ENSINO, 17, 2014, FortalezaCE. Anais [...]. Fortaleza - CE, 2014. 
DE PESQUISA EM EDUCAÇÃO EM CIÊNCIAS, 11, 2017, Florianópolis-SC. Anais [...]. Florianópolis-SC, 2017.

SAMPIERI, H.; COLLADO, F.; LUCIO, B. Metodologia de Pesquisa. 5. ed. Porto Alegre: Penso, 2013.

STRIEDER, R. B. Abordagens CTS na educação científica no Brasil: sentidos e perspectivas. 2012. 283 f. Tese (Doutorado em Ensino de Ciências) - Universidade de São Paulo, São Paulo, 2012.

STRIEDER, R. B.; KAWAMURA, M. R. Educação CTS: parâmetros e propósitos brasileiros. Alexandria - Revista de Educação em Ciência e Tecnologia, Florianópolis, v. 10, n. 1, p. 27-56, maio. 2017.

Recebido: 14 mar. 2020

Aprovado: 12 jun. 2020

DOI: $10.3895 /$ actio.v5n2.11778

Como citar:

SILVA, R. L. J. da.; STRIEDER, R. B. CTS nos anos iniciais do Ensino Fundamental: abordagens para a temática da água. ACTIO, Curitiba, v. 5, n. 2, p. 1-19, mai./ago. 2020. Disponível em:

$<$ https://periodicos.utfpr.edu.br/actio>. Acesso em: XXX

Correspondência:

Raimunda Leila José da Silva

Rua Albino Abadio de Oliveira, n. 09, Parque Laguna II, Formosa, Goiás, Brasil

Direito autoral: Este artigo está licenciado sob os termos da Licença Creative Commons-Atribuição 4.0

Internacional.

(c) (i) 